\title{
Positioning Informal Skills Learners in TVET System of Nepal ${ }^{1}$ \\ Durga Prasad Baral* \\ Kathmandu University School of Education, Lalitpur, Nepal
}

\begin{abstract}
The informal sector occupies a significant portion of employment in Nepal. More than eighty per cent of all employees work in this sector. These workers generally lack formal skills training and acquire skills while performing the work under the guidance of skilled workers. However, the technical and vocational education and training (TVET) system rarely recognises such informally learned skills at work. In this context, this paper explores the position obtained by informal skills learners in the existing TVET system of Nepal. I drew information from related literature, collected experiences of six informal skills learners as cases and incorporated views of eight experts through interviews. The study shows that informal skills learners are getting very little attention in the Nepali TVET system. In fact, the system is not valuing the contribution of local communities and institutions, industries, and enterprises in the development of skills. Furthermore, the study reveals that lacking awareness-raising and motivational programmes targeted to youth; and the government's unfavourable working approach to TVET. In this situation, I argue that obtaining a dignified position by informal skills learners depends on the value given to skills, work, and occupation. The paper concludes that Pervasive Loitering Syndrome (PLS) prevails across different layers of society. The PLS creates the situation of less valuing skills, work, and occupations, and ultimately the informal skills learners are devalued.
\end{abstract}

Keywords: TVET, informal skills, pervasive loitering syndrome

* Author Email: baraldurga@kusoed.edu.np https://orcid.org/0000-0002-6510-8106
ISSN: 2091-0118 (Print) / 2091-2560 (Online)

(c) 2020 The Author(s).

Journal homepages: ${ }^{1}$ http://www.kusoed.edu.np/journal/index.php/je

${ }^{2}$ https://www.nepjol.info/index.php/JER/index

Published by Kathmandu University School of Education, Lalitpur, Nepal.

This open access article is distributed under a Creative Commons Attribution (CC BY-SA 4.0) license. 
Positioning Informal Skills Learners in TVET System | 33

\section{Introduction}

The informal sector in Nepal is very dominant. More than 80 per cent of all workers in Nepal work in the informal economic sector (Asian Development Bank [ADB], 2015; Ministry of Labour and Employment, 2014). Informal workers, who generally have very little formal education, acquire skills informally while working. They learn skills through different means and in various settings. These different means have been categorised as formal, non-formal, and informal. Formal learning happens in educational establishments, which is structured and makes the provision of academic qualification and its certification. Whereas, non-formal learning happens outside formal academic institutions where learning may be structured but generally does not lead to certification (European Centre for the Development of Vocational Training [CEDEFOP], 2007; Misko, 2008). Informal learning which is acquired through daily life activities other than formal educational settings, and might not lead to any recognised certification (CEDEFOP, 2007; Misko, 2008). The workplace is one of the major places where one acquires skills informally during work. This paper focuses on adults and youth as informal skills learners who acquire occupational skills during the work.

In Nepal, the informal sector, including various traditional occupations, has been in practice for generations which shares a large part of total employment. Skills transfer system from senior craftsperson to novice skills learner is the rooted practice of skills learning in most of the traditional occupations. In such traditional apprenticeship, generally, a senior member of the family instructs skills and mentors junior members. Furthermore, even in the sector of other modern (non-traditional) occupations such as metal fabrication, auto-mechanics, fast-food businesses similar practice can be seen. But the skilled workers and craftspeople of those occupations often share their grievances that the society does not give appropriate value to their skills. Moreover, these workers also express their unawareness about the existing provisions of training and skills certifications. Besides, such skills acquisition practice is not incorporated in the mainstream technical and vocational education and training (TVET) system of Nepal.

In this regard, the experience of some other countries, particularly from African continent skills is exemplary in upgrading and assessment of the informal sector's 


\section{4 | D. P. Baral}

workers. Inclusion of informal apprentices (informal skills learners) through Dual Apprenticeship in Benin; recognition of informal apprentices through Business Associations in Ghana; involvement of private sector in quality control in Senegal and Niger; provision of direct financial support through vouchers in Kenya are some of such examples of TVET interventions in upgrading informal apprenticeship (International Labor Organization [ILO], 2012). Likewise, a survey study conducted in Bangladesh concluded that TVET reform was inevitable and was possible only through recognising informal skills learning in the informal sector (ILO, 2009). Considering the study result, the Bangladesh Government is implementing apprenticeship training programmes at present targeting both categories of apprenticeship — formal and informal, and more than 25 thousand people have already trained through the scheme (a2i, n.d.).

Nepal also accepted this concept theoretically for long. Realising the vitality of apprenticeship training, Industrial Trainee Training Act, 2039 (1982) made a provision of apprenticeship in the decade of nineties (Government of Nepal [GoN], 1988), it is never implemented in the country. Albeit late, the dual apprenticeship training is initiated recently with collaborative efforts of the Government of Nepal and the Swiss Agency for Development and Cooperation (SDC) through Enhanced Skills for Sustainable and Rewarding Employment (ENSSURE) project. However, the major focus of this project is not the informal skills learners, particularly working in the informal sector (Enhanced Skills for Sustainable and Rewarding Employment [ENSSURE], n.d.). With the similar collaboration of GoN and SDC, National Vocational Qualification System (NVQS) project is working at present and has drafted the proposed National Vocational Qualification Framework (NVQF) of the country (NSTB, 2018) which envisions the provision of Recognising Prior Learning (RPL). The RPL is expected to enhance the access of informal skills learners in recognising and certifying their skills. However, to pursue the goal of the NVQF, it is essential to understand the existing situation of informal skills learners and explore the way to attract them in the TVET system.

In this context, the primary purpose of this research is to explore and analyse the present situation and recognition of informal skills learners in the existing TVET system of Nepal. Particularly, it aims to seek the answer to the questions: 1) How informal skills learning has been incorporated in the current TVET system, and 2) Why 
Positioning Informal Skills Learners in TVET System | 35

informal skills learners are not valued by the TVET system? My proposition is that informal skills learners are not getting value from society and also are neglected by the TVET system of Nepal. I argue that the main reason for getting less value by informal skills learners is the existence of a phenomenon I call "pervasive loitering syndrome" (PLS) towards valuing skills, work and occupations among different tiers of Nepali society starting from a person to family, society, private sector as well as civil society and ultimately the polity of the country.

In the following sections, first, I present a brief introduction to the existing TVET and skills testing system in Nepal. Then, I provide concept and use of the terminology 'loitering' that I used in the phrase- 'pervasive loitering syndrome' to depict the perception of Nepali society towards valuing informal skills. Afterwards, I present the methodology and then three thematic sub-titles based on the information received from the research participants together with the discussion on how PLS exists in the Nepali society. Finally, I offer theoretical perspectives on the finding and present the conclusion of the study.

\section{TVET and Skills Testing System in Nepal}

In Nepal, the history of education and training generally goes back to the Hindu and Buddhist traditions such as Gurukul, Gomba and Vihar (Adhikary, 2005; Research Center for Educational Innovations and Development, 2007) as well as traditional occupational knowledge and skill-building system (Lama, 2016; Shrestha, 1991). Similarly, occupational classification based on caste and social groups was prominent for long. Informal skills learning was not directly mentioned in the periodic plans (1956-2019). However, it has been included indirectly under the provisions of preservation and promotion of traditional and local skills (National Planning Commission, 2019). Similarly, multiple attempts of organisations and management of TVET through national education programmes were made for long (Shrestha, 1991; Bista, 1991) (for instance, through Multi-Purpose Education System in 1967 and National Education System Plan in 1971).

However, the history of modern technical vocational education and training can be taken as of about forty years when some technical schools were established in different rural and industrialised locations of the country in the 1980s (Kafle, 2007). The Council for Technical Education and Vocational Training (CTEVT) was established in 


\section{$36 \mid$ D. P. Baral}

1989 as per the CTEVT Act 2045 [1988] as an apex TVET organisation in the country to coordinate, expand and maintain the quality of TVET provisions (CTEVT, 2018). Though CTEVT has the mandate of managing from the basic to the higher level of TVET (up to university level), its major focus is on the production of middle-level skilled technicians required for the country as well as for global labor market (ADB, 2015; CTEVT, 2016). The short-term vocational training is conducted mainly as part of project-based activities in support of different donors and involvement of different government and non-government organisations (ADB, 2015). Though the focus of such short-term training is on the disadvantaged group of people, the benefits of these training are mostly limited to the youth living in accessible locations (Bhattarai, 2014).

Coordination and collaboration among the actors are one of the essential features of a successful TVET system for increasing access to and maintaining the quality of, education and training. However, the TVET system of Nepal is said to be "fragmented" (ADB, 2015; Baral et al., 2019). Besides CTEVT, there are other government organisations such as Department of Cottage and Small Industries (DCSI) under the Ministry of Industry, Commerce and Supplies; Vocational Skill Development Training Center (VSDTC) under the Ministry of Labor, Employment and Social Security; Nepal Academy of Tourism and Hospitality Management (NATHM) under the Ministry of Culture, Tourism and Civil Aviation, and different institutions under some other ministries (Baral et al., 2019). Similarly, non-government, private sector and community-based organisations also run different TVET courses (ADB, 2015; Baral et al., 2019). In addition to TVET programmes being implemented in an uncoordinated manner, these are being run without assessing the demand of the labour market and the need of the people (Parajuli, 2013). These might have not yielding the expected results despite many TVET efforts made in the past.

The informal learners acquire skills at the workplace, which is relevant to meet the need of business, industry, and enterprises. Thus, recognising those skills of informal learners and attracting them to national TVET certainly contribute to bridging the gap between the skills and needs of the job market.

National Skill Testing Board (NSTB) has been conducting skill tests for almost four decades for both non-formal and informal learners (ADB, 2015; National Skill Testing Board [NSTB], 2018). The Skill Testing Authority (STA) was established in 1983, 
Positioning Informal Skills Learners in TVET System | 37

which got the responsibility of conducting skill tests and certification for skilled and semi-skilled workers. Later on, the Authority was converted into NSTB in 1989 along with the establishment of the CTEVT (NSTB, 2018). The scope of the NSTB includes identification of occupations, development of National Occupational Skills Standards (NOSS), organising skill tests, and providing certificates to the successful candidates (NSTB, 2018). To date, a total of 290 NOSS/ Occupational Profiles are developed and skills of 472,123 people tested. Among them, 450,257 persons passed the test and were certified by the Board (NSTB, 2018). This number of skill tested people is low in comparison with the huge volume of youth working in the informal sector (World Bank, 2019). There might be several reasons such as lack of information, disinterest in the process, access to the system, etc. for this. However, my argument on the low participation of informal skills learners in the skill-testing process in the TVET system is also related to 'loitering'. In the following section, I briefly mention the meaning of the loitering and its use in academia.

\section{Loitering: Meaning and Use}

The word 'loitering' is used in various contexts and fields. Nevertheless, loitering is mainly used for denoting an undesired behaviour of people. Those people who have either "abundance" of time or do not value time and spend their time in public spaces with activities such as gossiping, watching, wandering, etc. is generally understood as loitering (Amsa, 1986; Ener, 1999; Jabar et al., 2012).

Loitering is a historical phenomenon and has remained a problem in societies. The study conducted by Ener (1999) shows how nineteenth-century Egypt suffered from the laziness and loitering of marginalised rural people and how a state had to take measures for minimising the loitering of "lazy peasants" (Ener, 1999, p. 321). Similarly, regarding the loitering behaviour of workers of some textile industries in India, a study was conducted by Amsa (1986) when there was a rumour that the rate of loitering was high among the workers in the textile industry. The research was conducted to understand how the production was affected when workers loitered, particularly by being absent in the production line with multiple excuses and pretendings. The study showed that there was a direct relationship between the organisational culture and the attitude of loitering. Similarly, the study concluded that the dimension of loitering 


\section{8 |D. P. Baral}

differed in public and private organisational contexts. When loitering is taken as a "tradition", the degree of loitering is more critical (Amsa, 1986, p. 350).

A loitering phenomenon can spoil a society. Particularly, loitering of the youths and teenagers is very critical. Malaysia is one of the examples where such teenage students have been a headache of the government for long (Jabar et al., 2012). Though multiple measures have been taken by the government for preventing loitering from the children, those measures are not proven effective. Jabar et al. (2012) found that the main reasons for loitering by teenagers include releasing the tension, absence of works to do, and lack of recreational activities. In this sense, it can be understood that loitering is inherently a problem of a society that deviates the people from their regular activities.

In the case of Nepal, the term 'loitering' is rarely found used in literature. However, the term is widely used in informal conversations as well as in mass media (Khanal, 2020; Upadhyaya, 2020); Particularly, those activities related purpose-less walking, performing undesired activities as well as not fulfilling the duty by a person is understood as loitering. This terminology seems much more appropriate to denote the phenomena about which this paper is focussed and so will be used here.

\section{Methodology}

Premised on my belief in the existence of multiple realities and intersubjectivity, the paper follows a qualitative approach. I assume that the main sources of knowledge regarding informal skills learning are the informal skills learners themselves. Similarly, TVET experts who have long work-experience are other key sources of information in this study. Therefore, I collected information from these two categories of people-1) informal skills learners, and 2) TVET related experts.

Under the category of 'informal skills learners, individual cases of research participants, whom I met from September 2018 to June 2019, were developed. During this period, I interacted with 11 participants who were working in three different occupational enterprises. Among them, six informal skills learners were selected based on their consent and availability of time in the study. To maintain the anonymity of the research participants, I have used pseudonyms instead of the real names of individuals and organisations. 
Yuvaraj, a renowned metal-sculpture artist, runs his family traditional business that had been operating since ancestry. Jiwa, working in a sheet metal arts and crafts enterprise, is a young boy originally from the mid-hill of the country. He came to the capital city, Kathmandu at his adolescence. He learned arts and crafts skills during the work in a small metal enterprise for four years and shifted to one of the established metalcraft companies five years ago. Similarly, two adults, Damodar and Lambodar, are potters from Thimi, Bhaktapur who learned pottery skills from their ancestors and running their family enterprises. Ratna and Dinesh were selected as research participants from the occupation of motorcycle mechanics. Ratna is from a peasant family from the Kathmandu valley. He began his career in the field of the automobile since his adolescence and was running his motorcycle workshop. Similarly, Dinesh, a senior mechanic, was running his motorcycle workshop in the mid-city of Kathmandu.

Among the TVET experts, Gobinda was taken as TVET researcher who has been working in the national as well as international TVET sector for more than 20 years. Three TVET managers-Kanhaiya, Bhola, and Sanyog- have more than fifteen years of work experience as TVET managers in public and private institutions. Similarly, three TVET experts are from the private sector business and industry associations.

Nilakantha and Ganesh are from two industry associations, and Keshav is one of the renowned trade unionists of the country. Likewise, Bijaya is the only government officer from one of the leading TVET related government ministries.

For selecting the second category of the research participants, initially, I prepared the long list of the potential TVET experts. I selected eight 'experts' based on the criteria that they had at least ten years of working experience and represented one among different four sectors- government (3 Nos), intermediaries (1 No.), researchers (1 No.), and non-government institutions (3 Nos.) I prepared an open-ended interview checklist based on the interview guidelines (Burgi \& Kemper, 2018), and conducted conversation type interviews. Selected experts were contacted through telephone and email, and the dates of the interview were finalised. Among the eight experts selected, three were from out of Kathmandu Valley whereas the other five were from the capital city representing different TVET related institutions. The interviews were conducted during the period of March-April 2018. Each participant was interviewed for about an hour in an informal type of conversation. All interviews from both categories of research participants-informal skills learners, and TVET related experts—were 
recorded, which later on were transcribed and coded. This coding process helped me for generating three themes under the major theme that informal skills learners are getting a negligible position in the TVET system of the country. Three sub-themes were: 1) informal skills are less appreciated 2) insufficient awareness and motivational programmes, 3) existence of unfavourable working approach of the Government. In the following section, I present the theme and sub-themes based on the information obtained from the research participants.

\section{Informal Skills Learners: Are They Getting the Position?}

This section discusses the position of informal skills learners under three thematic sub-titles. The first theme discusses the recognition of informal skills learners in Nepal's TVET system. The two other themes discuss the awareness related activities run for the informal skills learners and governments approach towards informal skills learners.

\section{Informal Skills - Less Appreciated}

Nepal's skill development history lies on the foundation of traditional skills and traditionally practised occupations. However, in the name of modernisation, those skills and occupations have been neglected (Parajuli \& Das, 2013). Jiwa, a young metalcraft artisan, working in a metal sculpture industry in Patan, a historical place of metal arts and sculptures in the Kathmandu Valley, shared his life-story of struggle. He told me that he had to drop schooling because of the poor economic condition of his family. So, he jumped in the world of work. Gradually, he learned metal arts and crafts related skills and became a skilful craftsperson. With the satisfaction in his success as a skilled artisan, he expressed his anxiety. He told me that "though we are competent, skilled citizens, the state (education system) is not treating us as skilled people just because we do not have a certificate." In the interaction with Jiwa, it was obvious that he did not know about skills assessment and certification systems in the country. If he was informed, he might have participated in the skills testing in the occupation and appropriate level for his skills.

The version of Ratna, a senior motorcycle mechanic cum owner, regarding skills obtained during the work also expressed a similar opinion to Jiwa. Ratna opined that he prefers hiring experienced workers rather than non-formal vocational skills training graduates from CTEVT. He added that the informal skills learners who acquire skills Journal of Education and Research, Vol. 10, No. 1, 2020 
Positioning Informal Skills Learners in TVET System | 41

during their work "can perform every type of skill needed for their workshop" which is lacking in vocational skill training graduates. In this line, Ratna was expressing his dissatisfaction with the (government) system that their valuable contribution in producing skilled human resources as per the need of the local labour market was not valued.

Similarly, during the interview, Kanhaiya, Principal of one of the technical schools located in Eastern Tarai, expressed that in different rural parts of the country people are still performing their domestic and social activities based on their traditional knowledge and practices. The principal was worried that the present TVET system not only neglects those practices but imposes other types of skills development programmes. He questioned the interviewer that "what is not done by these communities?" and expressed that "they perform their farming, they rear cattle and do animal husbandry; they perform dairy, they do carpentry and masonry they need; and they prepare the roof for their houses et cetera." In this sense, on one side, traditional skills are disappearing, and on the other side, imposed skills are not being useful in the community.

The need for identification, preservation, and recognition of informal skills learning is also felt by the government official. Bijaya, a senior government official working in one of the Government Ministries and operating skills development training, accepts that "multiple informal TVET activities are existing in different sectors such as agriculture and forestry which need identification, preservation, and recognition". In a similar line, Sanyog, Principal of a government Technical School located in the southern plain of the country providing an example of Mithila Art expressed that "those people who are involved in different occupations and running their livelihood are (nowadays) anxious about the extinction of their art and skills." The problem regarding the development of such traditional arts and crafts are related to the interest of youth rather than its market demand. At present, despite having a good market, the youth are getting less interested in such an occupational skills sector. In this regard, another expert, Ganesh, an influential tourism industrialist and experienced handicraft entrepreneur expressed that "in the recent past, many people escaped from the handicraft sector and opted for academic education such as a doctor, engineer, etc." He further expressed that the new generation was feeling increasing markets of such traditional occupations. Particularly, the reason behind peoples' increasing attraction with those skills is due to increasing its linkage with tourism (Bhatta, 2016). So, he 


\section{2 |D. P. Baral}

believes there is a need for identification and recognition of those traditional occupational skills. For this, the existing skill-testing should be more extensive and accessible for the assessment and certification of those traditional occupational skills.

Not only the traditional occupations but also other occupational skills acquired informally by workers in the industrial setting are not being addressed by the national TVET system. Those industries are compelled to perform skills development training in their efforts. This is the experience of my research participant. Bhola, one of the experienced TVET managers working in one of Regional Offices of a leading TVET institution, said, "Industries, whether they are small, medium or large, do operate training for their workers on their own. They provide opportunities to their raw apprentices to learn skills by keeping them together with the skilled workers." Thus, from the experts, it is clear that real, needy people, working in small traditional occupations to modern large manufacturing industries, are not less connected with the existing national TVET system. Therefore, it is necessary to coordinate and combine such individual skills development efforts of different institutions and organisations in the national TVET system through identification, recognition, and certification.

\section{Insufficient Awareness and Motivational Programmes}

According to the research participants, the TVET system of Nepal is lagging in two major aspects. First, it is not able to attract unemployed youth to skills development through motivational programmes. The second, TVET system is rarely disseminating the information to youth regarding the existing provisions of training and skills test.

Yuvaraj, a metal-sculpture artist as well as an informal skills learner, was found anxious about the existing information dissemination of the TVET system that most of the skilled workers are not aware of the existence of the skill-testing system of the country. He opined "Those youth who are either weak in education, or not able to continue the school due to various reasons are working in different informal sectors. They should be attracted to further training and should be informed about the skills testing provisions." In a similar version, TVET expert, Nilakantha, a leader of commodity associations, sees unavailability of work is not only the reason for present youth unemployment. He argued that this problem was due to the absence of motivational activities related to skills and work. 
Positioning Informal Skills Learners in TVET System | 43

Consequently, he further expressed, the youths are mostly "loitering without work in unproductive activities". He emphasised conducting both the skills development and awareness-raising motivational programmes in parallel. He insisted "when the youth are motivated for obtaining skills, they will search the training for the skill training opportunities. He further added, "When youth have skills and are motivated to work, they certainly get the employment." Of course, the first and foremost necessity for the youths is to have employable skills at hand and a motivated mindset for work.

Although Nepal's economy is dominated by the informal sector and traditional occupations, it is facing multiple challenges. Pottery is an example of such an occupation. This family-run occupation, mainly of Prajapati caste group of Bhaktapur and Thimi area, is one of such occupations on the verge of extinction due to different reasons. When I learned during the interview, Damodar, a potter in Thimi, was not teaching pottery skills to their son. I asked whether his son wanted to learn the skills. Damodar straightly expressed that "the son wants, but we (parents) don't want to teach them the (pottery) skills". This shows that even senior members of the family do not want their children to continue their occupation. The family of Damodar thought that it (pottery skills learning) could hamper the son's educational performance in the school. In this context, the pertinent questions can be raised about the responsibility to preserve, recognise, and promote the traditional occupations and skills that whether it is of a person, family, or of the TVET system.

Both the TVET experts and informal skills learners have a common understanding that there is a lack of awareness-raising and motivational programmes in the TVET system. Information dissemination is not only the problem of the Nepali TVET system but also in the countries of the South Asian Region (ADB, 2009). This situation indicates mainly two things. Firstly, it shows the existence of a systemic problem in the field of awareness-raising and information dissemination; and the second, it shows the immediate need of strengthing the mechanism of information dissemination and awareness-raising on the part of Nepali TVET system.

\section{Unfavourable Working Approach of the Government}

Both categories of research participants, informal skills learners, as well as TVET experts, are not satisfied with the working approach of the government, especially valuing informally learned skills. For instance, Dinesh, an informal skills learner 


\section{4 | D. P. Baral}

working as a senior motorcycle mechanic, expressed his dissatisfaction with the working approach of the government by saying that "every person can open a workshop everywhere without assessment of skills." He blamed that the (state) system is neither attracting people for acquiring skills nor controlling the quality of the motorcycle workshops, which is directly associated with the safety of people. He opined that there should be certain criteria of the minimum skill level of the person opening a workshop even if they are informal skills learners.

During the interview, Lambodar, an adult potter in Thimi, expressed his grievances to the Government that it is not looking after traditional occupations. He mentioned that there was an effort of modernising the (traditional) occupation to ceramic production in the past through an INGO which could not run the programme long as "most of the people did not want to abandon the traditional practices." Lambodar's expectation was for government intervention in this occupational area so that culturally associated skills could be survived.

Gobinda, a TVET researcher, in line with Dinesh and Lambodar, expressed his dissatisfaction, indicating deviation in the implementation of some donor-driven projects. He stated that "the projects (running at present) originally designed for targeting workers of small enterprises are deviating and targeting to big enterprises." Although there are multiple policy provisions for skill development, these policies do not necessarily convert into practice. The implementation part is generally found as problematic in Nepal (Sharma, 2014). Informal skills learners are also not exceptional cases.

It is also found that some institutions and officials even do not consider career progression as an inevitable component of skills development. Bijaya, a government official, naively expressed that the main purpose of the training was to establish the "self-enterprise". He did not see any necessity for career progression. The TVET and Skill Development Policy (2007), envisions the career progression to be addressed by the provision of Nepal Vocational Qualification System. The system, further, expects to ensure that "all modes and places of learning, formal or informal, in-school or onthe-job can be recognised and used for progression and transition" (ADB, 2015, p. 27). The system also envisions for the massive implementation of recognising all sorts of prior learning. So, it will be too early to evaluate the outcome of NVQS to bridge the 
Positioning Informal Skills Learners in TVET System | 45

lacking part of the present TVET system to address the concern expressed by research participants about informal skills learners. The following paragraphs discuss the contributing elements responsible for getting less attention from informal skills learners.

\section{Informal Skills Learners: Victims of Pervasive Loitering-Syndrome}

In every society, socio-economic development is shaped according to the contribution made by its actors. The major actors range from individuals to family, society, private sector, and civil society and polity of a country. In the case of Nepal, the informal sector plays a vital role in the socio-economic development of the country.

From the interaction with my research participants, I reflect that the situation for informal skills learning is unfavourable in the country. The social actors from family to society, the private sector, and the government are generally found less valuing informal skills, work, and occupations. This has ultimately hindered the informal skills learners from getting an appropriate position in the national TVET system. Why skills, work, and occupations are not getting appropriate value, and thus why informal skills learners are not getting sufficient opportunity for progressing their career? Based on the findings, the answer can be drawn because we are not doing what we have to do. I use a relevant Nepali word "Baralinu" for denoting this phenomenon which bears a negative connotation and means spending time in an undesired activity not valuing the time (Nepal Pragya Pratishthan, 2040 [1983]). To express the phenomena of "Baralinu", I use an appropriate phrase as PLS which is prevalent not only at the individual or family level but also at the society, business and industry as well as in the government level. As the phenomenon of loitering is spreading at all levels of the Nepali society, I have used the adjective 'pervasive' in front of the word 'loitering'. Similarly, I have used the word 'syndrome' for expressing the 'undesired' symptoms.

Business and industry people are those who are among the major employment sectors are the appropriate people characterising the nature of present youth. Though there are some very inspiring examples of youth entrepreneurship, the majority of the cases are, unfortunately, not such. As one of the TVET experts, Nilakantha expressed that present youths were overly associated with "politics" and "they loiter without work". This version of the research participant is in line with the expression of the present youth themselves that they are of a more "relaxing" nature (Karki, 2019). Not 
only in the farmland but also the sector of construction, service, and manufacturing, workers are being imported from neighbouring countries. In the domestic labour market, there is a shortage of labourers. The expression of one journalist seems convincing that "Nepalis are said to work hard, but only when they are outside Nepal. At home, manual work is regarded as shameful" (Chitrakar, 2018). Seeing the Jagire (white-collar job) mentality and the nature of average youth spending time in unproductive activities such as playing cards and carrom neglecting work at their own home supports the assumption being in a situation where one does not need to be involved in manual labour for a living (Chitrakar, 2018). There might be multiple reasons for the existence of such a situation that needs to be researched separately. However, one among those might be, as Bista (1991) mentioned, the "white-collar" mentality of Nepali society, which is associated with the historical occupational hierarchical system. Whatever the reasons may be, the role of individual youth, in general, can be pictured as 'loitering' in valuing skills, work and occupations.

Though the degree of discrimination based on hierarchical caste systems is in the direction of improvement, still families are influenced by such a system at present. Occupational role and the tag of "untouchability" to those caste groups, families try to escape their children from occupations that involve blue-collar jobs. As Bista (1991) and Upadhyay (1987) mentioned, it seems still valid that the primary objective of youths for having an education and training certificate is for getting a good jagir which means a white-collar job. This tendency can be taken as one of the reasons for massive unemployment in the country. Even those groups of people who were practising traditional occupations since generations have also nowadays started to divert the occupation of their children (Chapagain, 2000). Of course, there might be other perspectives of guardians for making such decisions such as better economic benefits but even in those occupations where the earning is much higher than the average income, the attraction of people to those occupations, generally, seems less as one of the research participants mentioned. That is, some traditional occupational groups have massively started to abandoning their occupations (Chetry, 2010). In addition to giving lower value to work and skills, people only prefer to send their children to any vocational skill development training as a second or, say, last resort. They value the higher academic qualifications of their children rather than employment-oriented skills at hand (ADB, 2009; Bista, 1991). This type of mentality rooted in common Nepali 
Positioning Informal Skills Learners in TVET System | 47

families certainly discourages the traditionally established culture of valuing skills, work, and occupation among certain occupational groups.

Family is an institution guided by social norms and values. The Nepali society suffers from the stratification of multiple groups of castes, classes, and ethnicities from the historical period, and the footsteps of which are still prevalent despite very strict legal provisions upon discriminatory practices. As Bista (1991) highlighted at the beginning of the decades of nineties, providing the cultural history of Nepal, those skilled people such as tailor, cobblers, metal workers, and other different craftspeople who were directly contributing to the national production were tagged as Sudra which means the caste with low status (Bista, 1991). Within these three decades, some positive signs on equity and equality of people seem to be arising; however, injustice and inequality are still prevalent in different ways (Chetri, 2018; Subedi, 2016). Overall, it can be said that Nepali society in general, is contributing less towards valuing skills, work and occupation and ultimately the informal skills learners. Again, as we characterise individual and family as institution loitering in the sense of less valuing work-culture, we can give the same label to societies suffered from PLS as it is, in overall, still not providing higher value to skills, work, and occupation as contemporary globalised time demands.

When we search for what role the private sector, which can be taken as the principal element of the informal sector, is playing, we cannot find a satisfactory response. Though it is one of the major actors of skills development activities, its main objective seems limited to making a profit (Support to Knowledge and Lifelong Learning Skills [SKILLS], 2016). In Nepal, the proactive role of the private sector on skills development is, generally, limited to operating private technical institutions (SKILLS, 2016). Valuing skills and capabilities of informal skills learners and reducing exploitation of workers by enhancing their mobility seem negligible as some TEVT experts mentioned during the interview (Gobinda, Keshav). Not only workers but also industries and associations are being engaged in the fragmented political activities for the sake of their benefits (Norwegian Institute of International Affairs, 2017) with very limited concerns of real workers. The similar passive role can be seen on the part of the civil societies. In recent years "the proliferation of civil societies organisations (CSOs) have now produced a surplus of elites who tend to dominate and control both the state 
and society on their terms and are merely concentrated in the urban centers" (Sharma, 2012, as cited in Bhatta, 2016, p. 81).

Thus, like other elements - individual and family, as well as societies - the private sector and civil societies in Nepal, are also suffering from PLS as they are not doing what is expected of them in favour of informal skills learners and the unemployed youth.

There might be multiple probable answers to the question I raised at the beginning of this section: Why skills, work, and occupations are not getting appropriate value and thus why informal skills learners are not getting sufficient opportunity for progressing their career. However, no one would deny that the main responsibility of establishing a system of valuing informal workers, designing and implementing massive awareness programmes, and changing the mindset of general to the responsible officials ultimately lies in the state's polity. Nevertheless, the government not only in the past but also at present, is continuing its ritualistic practice of conducting TVET activities, without desired contemporary changes in the work culture. Even after the political transformation to the federal system in 2015, the state is failing to provide the desired services to the people and maintain stable governance (Nightangale et al., 2018). In this sense, like an individual and family, society, and the private sector, even the government itself is seen affected by the PLS, particularly in the case of valuing skills, work and occupation; and ultimately the informal skills learners. As the ILO (2016) finds, "how to inculcate a positive work culture by changing the value system associated with work and employment in Nepali society" (p. 35) has remained a challenge. Thus it recommends that "Reforming education system from general knowledge-based education to vocational, occupational skill-focused and work-related education at all levels" (ILO, 2016, p. 39) seems very pertinent and valuable.

Thus, from this discussion, it is evident that informal skills learners are getting a negligible position in the existing TVET system of Nepal and one of the main reasons behind this is the existence of PLS across different layers of the Nepali society. In the following section, the theoretical perspective on the existing phenomena for getting a trivial position by informal skills learning is provided. 


\section{Informal Skills Learners and Loitering Youth: Neglected Actors}

The informal skills learners, as mentioned in the initial paragraphs of the paper, are youth and adults who generally drop out of school education and enter directly to work of informal nature. In most cases, they work and learn skills simultaneously in informal enterprises. Being informal skills learners, they are also part of the skills development system of the country. However, the existing system does not reach in majority cases of those informal learners as well as the "loitering youth". Besides, those informal learners are not sufficiently recognised by the TVET system. Youths who dropped out of school but not at work are also the potential informal skills learners. This study explored that informal skills learners have not been, in general, attracted to the TVET system. There might be three pertinent reasons behind it. Firstly, they are not well aware of the existing skills testing provision of the country. Furthermore, there is a lack of minimal motivational programmes for youth participation in the skill-testing. Secondly, informal skills learning enterprises, including community organisations, business, and industries, are rarely included in the TVET system. And, finally, the working approach of the key actor, government, has given very less attention to informal skills learners.

In this situation, I applied the concept of field and habitus of Bourdieu. According to Bourdieu and Wacquant (1992), "the field is a critical mediation between the practices of those who partake of it and the surrounding social and economic conditions" (p. 105). Similarly, according to Swartz (1997), Bourdieu's field means "arenas of production, circulation, and appropriation of goods, services, knowledge, or status, and the competitive positions held by actors in their struggle to accumulate and monopolise these different kinds of capital" (as cited in Power, 1999, p. 50). Here, in Bourdieu's concept of habitus, the TVET system is the main field where the informal skills learners and loitering youths are also the actors. According to Anheier et al. (1995), "the positions of various agents in the field are determined by the amount and relative weight of the capital they possess" (as cited in Ritzer, 2011, p. 533). It indicates that if informal skills learners were the influential actors with a competitive position, they certainly would get recognised and get appropriate positions in the TVET system. 
However, the situation is not like this in the case of the Nepali TVET system. Why those actors of the TVET field are not informed, attracted, and included in the skill development and recognition process is the pertinent question of the present days. There might be multiple reasons for this. One of the major reasons, as mentioned, maybe a lack of economic, social, and cultural capital (Bourdieu \& Wacquant, 1992) with those youths who are either unemployed or are, willingly or unwillingly, following informal working and learning path without searching opportunities for the recognition of their skills. Furthermore, the "common sense" (Holton, 2000, as cited in Ritzer, 2011, p. 531) of informal skills learners (giving less value to occupational skills and having general education mentality) as habitus excludes them from searching opportunities for skills recognition. On the other side, the "structured structure" (Bourdieu \& Wacquant, 1992, p. 139) of the public TVET institutions rarely in favour of the drastic reform of the system targeting informal skills learners and loitering youth. They prefer continuing the practice of conducting formal and non-formal training as "structuring structure" as Bourdieu conceptualised (Bourdieu \& Wacquant, 1992, p. 139) rather than making decisions in favour of informal skills learners.

As the social structure as field reproduces the habitus, it seems that the existing PLS continues to be effective. However, Bourdieu also sees that the change is possible through particular conditions, including changing habitus (Yang, 2014). Habitus acts automatically below the "level of consciousness" (Bourdieu, 1990; p. 73) of a human, but it does not mean that it cannot be changed. Habitus can be changed through different conditions (Bourdieu \& Wacquant, 1992). When habitus does not fit with the field, the level of consciousness increases (Yang, 2014). Furthermore, the contemporary changing from the traditional to open society encourages changing the existing habitus (Yang, 2014); in the particular case, PLS. According to Bourdieu, it is difficult to hold and continue the dispositions during the "crisis or sudden change" (Bourdieu, 2000, as cited in Yang, 2014, p. 1530). Thus, it is clear that though PLS as habitus is rooted in the society (as a field), it can be expected that those practices running for long are changeable through different means including the situation of crisis. 
Positioning Informal Skills Learners in TVET System $\mid 51$

\section{Conclusion}

Nepali society has encountered multiple crises - both natural as well as human borne - in history. The present global crisis created by the pandemic of COVID-19 has alarmed not only the Nepali society but also other countries of the globe, threatening the coherent existence of humanity. All countries of the world-in greater or lesser account - are influenced by this crisis (Buheji \& Ahmed, 2020). Particularly the vulnerability of people living in the underdeveloped context is much higher. Nepal also lies under the category of highly vulnerable countries as more than eighty per cent of the total employment is in the informal sector. It is estimated that around two million of such informal jobs are likely to be disrupted. Furthermore, a huge mass of foreign employment migrant youth — which is estimated as nearly three and a half millionalso highly affected by the present Covid-19 crisis (ILO, 2020). A considerable portion of this youth mass also returning losing job there, mostly in the Gulf countries, Malesia and India. It indicates the difficult days ahead. On the one hand, most of the economic sectors such as tourism, manufacturing, and different informal occupational sectors are being adversely affected by the pandemic whereas, on the other hand, the country's remittance inflow is drastically going to decrease (ILO, 2020). It will certainly diminish the availability of employment in the country. All layers of the Nepali society-from a person, a family to the private sector, and polity of the country - are guessed to be more or less affected. The crisis is expected even for maintaining the livelihood of the family. In such a situation, based on the theoretical insight provided by Bourdieu, it can be expected that the present crisis can be a good 'ice-breaker' for changing the long-rooted PLS as habitus. However, there are no other options than waiting and seeing to reach to the real conclusion.

This paper tried to shed light on the present situation of informal skills learning and the position informal skills learners obtain in the TVET system of Nepal. Particularly, the paper focused on explaining how the Nepali TVET system is targeting its programmes to the youths who learn occupational skills during their work. Valuing skills, work, and occupation is the prerequisite for the establishment of a broader system of recognising informal skills learning. However, the situation of recognising informal skills learning is less satisfactory in the context of Nepal in a broader sense. One of the reasons behind this situation is the PLS existing across different levels of society and amongst youth. It is also discussed with the theoretical framework of 


\section{$52 \mid$ D. P. Baral}

Bourdieu that the existence of PLS can be changed through certain conditions, such as facing a crisis. One such situation can be the challenge created to the youth as well as the Nations on how to create and sustain employment for the mass volume of foreign employment returnee migrants. The paper concludes that the informal skills learners will get appropriate recognition when they are valued by the TVET system, including individuals and society.

The PLS, which was the focus of this study, found ease to perceive but difficult to prove. This is because the pervasiveness of the phenomenon in different layers of society was agreed and expressed by the people but found very scarcely researched and written. So, I had to work with the support of limited literature. However, this research has opened the avenue for further research in multiple topics related to work attitude and viable approaches for struggling against the PLS.

\section{Note}

${ }^{1}$ The concept of writing this paper emerged when I got an opportunity to conduct in-depth interviews with ten experts from the technical and vocational education and training (TVET) field working in different parts of the country. The interview was the part of a collaborative research project named LELAM TVET4INCOME (Linking Education and Labour Market: Under what conditions can TVET improve the income of the youth) in which five countriesBenin, Chile, Costa Rica, Nepal, and Switzerland- are working together. My curiosity about how national TVET system in Nepal considers workers' skills obtained informally during the work became the topic of the research when almost all ten TVET experts expressed their dissatisfaction towards the present TVET system mentioning that it is not being able to launch youth-centred TVET programmes including valuing informal skills learning.

\section{Acknowledgements}

I thank the Swiss Agency for Development and Cooperation (SDC), the Swiss National Science Foundation, and SDC Nepal for financing the research. I am grateful for the inputs and support provided by Prof. Mahesh Nath Parajuli and Prof. Dr. Ursula Renold for the completion of this paper. I would also like to thank Mr. Prakash Kumar Paudel, KUSOED, for his support in editing and framing the paper.

\section{References}

a2i. (n.d.). Skills 4 decent employment. https://a2i.gov.bd/skills/ 
Positioning Informal Skills Learners in TVET System | 53

Adhikary, P. K. (2005). Educational reform for linking skills development with employment in Nepal. In M. Singh (Ed.), Meeting basic learning needs in the informal sector (pp. 215-228). Springer.

Amsa, P. (1986). Organisational culture and work group behavior: An empirical study. Journal of Management Studies, 23(3), 347-362.

Asian Development Bank. (2009). Good practices in technical and vocational education and training.

Asian Development Bank. (2015). Innovative ideas in technical and vocational education and training for the accelerated human resource development in South Asia: Nepal.

Baral, D. P., Kemper, J. M., \& Maldonado-Mariscal, K. (2019, December 21). Country case study on technical vocational education and training (TVET) in Nepal (LELAM Working Papers, No. 7). KOF Swiss Economic Institute, ETH Zurich. https://r4d.tvet4income.ethz.ch/publications/working-paper-series.html

Bhatta, C. D. (2016). The interface between the state and civil society in Nepal. Dhaulagiri Journal of Sociology and Anthropology, 10, 63-91. https://doi.org/10.3126/dsaj.v10i0.15881

Bhatta, K. (2014). How can vocational education and training (VET) play an important role on poverty reduction in Nepal? Technical and Vocational Education and Training Development Journal, 1(14), 71-75.

http://ctevt.org.np/files/Research\%20Journal\%202014.pdf

Bista, D. B. (1991). Fatalism and development: Nepal's struggle for modernisation. Orient Longman.

Bourdieu, P. (1990). The logic of practice. Polity.

Bourdieu, P., \& Wacquant, L. (1992). An invitation to reflective sociology. Polity

Buheji, M., \& Ahmed, D. (2020). Foresight of Coronavirus (COVID-19) opportunities for a better world. American Journal of Economics, 10(2), 97-108.

https://doi.org/10.5923/j.economics.20201002.05

Burgi, J., \& Kemper, J. (2018). Expert interview guideline: Finding programs for the asset mapping of TVET programs for LELAM TVET4Income project. Unpublished manuscript.

Chapagain, D. (2000). Contract labor in Nepal. Proceedings of the ILO Seminar, 1-33. Chetri, T. B. (2018). Federal Democratic Republic of Nepal: Deepening problems and prospects. Journal of Political Science, 18, 114-142.

Journal of Education and Research, Vol. 10, No. 1, 2020 
54 | D. P. Baral

Chetry, D. B. (2010). Changing the occupational patterns among the Bishwakarmas: A case study of Hemja VDC. Himalayan Journal of Sociology \& Anthropology, 4, 4960. https://doi.org/10.3126/hjsa.v4i0.4667

Chitrakar, A. (2018, November 14). Success in Nepal means not having to work:

Nepalis work hardest when they are outside Nepal.

https://www.nepalitimes.com/opinion/success-in-nepal-means-not-having-to-work/

Council for Technical Education and Vocational Training. (2016). Labour force survey: Analysis of emerging needs of technical human resources in the country.

Council for Technical Education and Vocational Training. (2018, December 6). About us. http://ctevt.org.np/page.php?page=1

Ener, M. (1999). Prohibition on begging and loitering in nineteen-century Egypt. Die Welt des Islams, 39(3), 319-339. https://doi.org/10.1163/1570060991570668

Enhanced Skills for Sustainable and Rewarding Employment. (n.d). Key project components. http://enssure.org.np/key-project-components

European Centre for the Development of Vocational Training. (2007). Recognition and validation of non-formal and informal learning for VET teachers and trainers in the EU member states.

Government of Nepal. (1988, November 13). Council for Technical Education and Vocational Training act, 2045 [1988].

Government of Nepal. (1994, June 13). Council for Technical Education and Vocational Training Rules, 2051 (1994).

Government of Nepal. (2015). Constitution of Nepal.

Government of Nepal. (2015). Youth vision - 2025 and ten-year strategic plan.

Government of Nepal. (2018). Budget speech of F.Y. 2018/19.

http://mof.gov.np/uploads/document/file/speech_english_20180715091522.pdf

International Labor Organization. (2009). Survey and assessment of formal and informal apprenticeships in Bangladesh.

International Labor Organization. (2012). Upgrading informal apprenticeship: a resource guide for Africa.

International Labor Organization. (2016). The future of work in Nepal.

International Labor Organization. (2020). Informal economy in Nepal.

https://www.ilo.org/kathmandu/areasofwork/informal-economy/lang--en/index.htm

Journal of Education and Research, Vol. 10, No. 1, 2020 
Positioning Informal Skills Learners in TVET System | 55

Jabar, F. A., Razak , N. H., Wahid, S. N., Rahman, M. Z., \& Paino, H. (2012). Loitering culture: Need or want. International Journal of Learning \& Development, 2(2), 161169. https://doi.org/10.5296/ijld.v2i2.1633

Kafle, A. P. (2007). Workforce development in Nepal: Policies and practices. Asian Development Bank.

Karki, D. (2019, February 19). Bro, how can I help you? The Kantipur Daily (26th Anniversary Special Issue).

https://ekantipur.com/feature/2019/02/19/155057159144787394.html

Khanal, C. K. (2020, March 25). People welcome lockdown as key to contain COVID19. The Rising Nepal. https://risingnepaldaily.com/main-news/people-welcomelockdown-as-key-to-contain-covid-19

Lama, S. (2016). Nepalese society in response to TVET programmes. Himalayan Journal of Sociology and Anthropology, 7, 155-174.

https://doi.org/10.3126/hjsa.v7i0.17155

Lamichhane, R. H. (2013). Strategic directions for CTEVT for skilling Nepal. Technical and Vocational Education and Training Development Journal, 14(1), 14-22.

http://ctevt.org.np/files/Research\%20Journal\%202013.pdf

Ministry of Education. (2007). Non-formal education policy.

Ministry of Labour and Employment. (2014). National employment policy 2071.

Ministry of Science and Technology. (2018). Education information 2074 (2016-17).

Misko, J. (2008). Combining formal, non-formal and informal learning for workforce skills development. National Centre for Vocational Education Research.

https://files.eric.ed.gov/fulltext/ED503360.pdf

National Planning Commission. (2019, July 20). Periodic plans.

https://www.npc.gov.np/en/category/periodic_plans

National Skill Testing Board. (2018). National Skill Testing Board.

https://www.nstb.org.np

Nepal Pragya Pratishthan. (2040 [1983]). Nepali brihat shabdakosh [Nepali extensive dictionary].

Nightangale, A. J., Bhattarai, A., Ojha, H. R., Sigdel, T. S., \& Rankin, K. N. (2018). Fragmented public authority and state: Un/making in the 'new' Republic of Nepal. Modern Asian Studies, 53(3), 849-882.

https://doi.org/10.1017/S0026749X16000500

Journal of Education and Research, Vol. 10, No. 1, 2020 
$56 \mid$ D. P. Baral

Norwegian Institute of International Affairs. (2017). Nepal: A political economy analysis.

Parajuli, M. N. (2013). Rhetoric of developing technical and vocational education and training (TVET) in Nepal: Analysis of the financing of the sub-sector. Technical and Vocational Educational Development Journal, 1(13), 58-68. http://ctevt.org.np/files/Research\%20Journal\%202013.pdf

Parajuli, D. R., \& Das, T. (2013). Indigenous knowledge and biodiversity: Interconnectedness for sustainable development. International Journal of Scientific and Technology Research, 2(8), 220-224. http://www.ijstr.org/finalprint/aug2013/Indigenous-Knowledge-And-Biodiversity-Interconnectedness-ForSustainable-Development..pdf

Power, E. M. (1999). An introduction to Pierre Bourdieu's key theoretical concepts. Journal for the Study of Food and Society, 3(1), 48-52.

https://doi.org/10.2752/152897999786690753

Research Center for Educational Innovations and Development. (2007). Education in

Gumbas, vihars and gurukuls in Nepal: Linking with mainstream education.

Ritzer, G. (2011). Sociological theory. McGraw-Hill

Sharma, T. N. (2014). Importance of Nepal vocational qualification framework.

Technical and Vocational Education and Training Development Journal, 1(14), 1-

11. http://ctevt.org.np/files/Research\%20Journal\%202014.pdf

Shrestha, S. M. (1991). Historical analysis of vocational education in Nepal

[Unpublished doctoral dissertation]. Virginia Polytechnic Institute and State University.

Subedi, M. (2016). Caste/ethnic dimensions of change and inequality: Implications for inclusive and affirmative agendas in Nepal. Nepali Journal of Contemporary Studies, 16(1-2), 1-16.

Support to Knowledge and Lifelong Learning Skills. (2016, June). Assessment of ways for facilitating private sector's productive engagement in TVET.

https://www.undp.org/content/dam/nepal/docs/projects/facilitating-the-privatesectors-engagement-in-technical-and-vocational-education-and-training-(tvet)-innepal.pdf

Suwal, R., \& Pant, B. (2009). Measuring informal sector economic activities in Nepal.

Paper presented at the IARIW-SAIM Conference on "Measuring the Informal Economy in Developing Countries", Kathmandu, Nepal.

Journal of Education and Research, Vol. 10, No. 1, 2020 
Positioning Informal Skills Learners in TVET System | 57

Upadhyay, K. D. (1987). Factors associated with socialisation in Nepal. Occasional Papers in Sociology and Anthropology, 1, 94-104.

https://doi.org/10.3126/opsa.v1i0.1059

Upadhyaya, N. P. (2020, March 12). Nepal: Arrival of yet another arrogant and aggressive Indian envoy. http://telegraphnepal.com/nepal-arrival-of-yet-anotherarrogant-and-aggressive-indian-envoy/

World Bank. (2019). The World development report 2019: The changing nature of the work.

Yang, Y. (2014). Bourdieu, practice, and change: Beyond the criticism of determinism. Educational Philosophy and Theory, 46(14), 1522-1540. https://doi.org/10.1080/00131857.2013.839375

\section{To cite this article:}

Baral, D. P. (2020). Positioning informal skills learners in TVET system of Nepal. Journal of Education and Research, 10(1), 32-57. https://doi.org/10.3126/jer.v10i1.31897 